\title{
Plattform I „Engel der Geschichte“
}

Malte Ewert, Projektleiter Plattform I

Eine Installation mit Performance im Rahmen des Großprojektes der Fachhochschule Osnabrück, Standort Lingen (Ems), Institut für Theaterpädagogik, mit vielen lokalen Kooperationspartnern

Ort: Im zukünftigen Fachhochschulstandort (ehemaliges Eisenbahnausbesserungswerk) jenseits der Bahn, April bis Mai 2005

\section{Ein Nachwort}

Am Beginn der Konzeptentwicklung stand der für mich als Dozent der Kunstschule Lingen und künstlerischer Leiter der ersten Plattform des Modellprojektes 2005 bis 2006 sehr befriedigende, sehr animierende Fachdiskurs auf der Suche nach einem gemeinsamen, spartenübergreifenden, sinngebenden Kunstbegriff.

Er sollte auf der Ebene der Lehre und an der Schnittstelle von Theaterpädagogik und Kunstpädagogik die ideologische Perspektive, den theoretischen Überbau zur Begründung der kunstphilosophischen ästhetischen Vermittlungsarbeit definieren.

Prof. Dr. Bernd Ruping, Fachhochschule Osnabrück, Standort Lingen (Ems), Leiter des Instituts für Theaterpädagogik, gab die entscheidenden Impulse mit umfangreicher Fachliteratur zu Walter Benjamins sehr aktuellem Geschichtsbegriff: zu seinem Engel der Geschichte. Dieses Bildsymbol ist zum mächtigen, alles prägenden nachhaltig bewegenden Inhalt unseres theatralischen Großprojektes geworden.

Wenn dieser Engel weiter leuchtet, wenn sich unter ihm etwas Wunderbares ereignet hat, das von ganz vielen als großes Gesamtkunstwerk erlebt worden ist, bleibt für mich, der beim Event-Abend nicht dabei sein konnte, bis heute ein immer noch anhaltendes, ungemein geiles Gefühl aus Dankbarkeit, Stolz, Glück und Befriedigung - weil ich bewusst nicht so sehr als gestaltender Künstler, sondern vielmehr als provozierender, animierender Kunstvermittler helfend erfolgreich war.

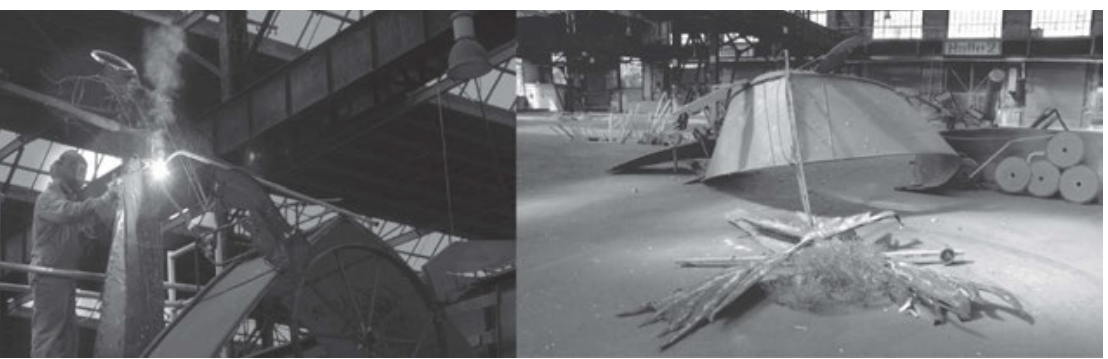


Kunst haben wir alle zusammen daraus gemacht. Diese Qualität, dieses Niveau, dieses Gesamtkunst-Wunder zu wiederholen, wird schwierig sein. Auf ein Neues also!

1. Projekte fangen vorher an: Kontinuität der Kooperation durch frühere Projekte mit der Fachhochschule, Institut für Theaterpädagogik.

2. Partizipatorisches Arbeiten I mit Prof. Dr. Bernd Ruping über das Finden eines gemeinsamen Kunstbegriffs bei Walter Benjamin und wie der „Engel der Geschichte“ (Benjamin) den „Sang der Maschinen“ (Berthold Brecht, Gedichte) ${ }^{1}$ veränderte.

3. Partizipatorisches Arbeiten II mit Achim Schülke (Polizeibeamter a.D.) am Bühnenbild in Halle I.

4. Partizipatorisches Arbeiten III mit MotorradfahrerInnen zum „Großen Tor von Mussorgski“.

5. Partizipatorisches Arbeiten IV mit Nadine Giese (wissenschaftliche Mitarbeiterin des Instituts für Theaterpädagogik), mit einem anderen Engel, von Paul Klee (Grafik „Der Engel bringt das Gewünschte“), Elektra und Krankenschwestern.

6. Partizipatorisches Arbeiten V im akzeptierten Schlussbild der „Chaoskids“ der Nacht, „Engelsturz“.

7. Partizipatorisches Arbeiten VI für Danksagungen und Nachklänge mit $8+30$ Engeln mit Geschichten.

8. Partizipatorisches Arbeiten VII für Band I Lingen. Stadt der Kulturen. sang der maschinen. Die Performance im Eisenbahnausbesserungswerk am Campus Lingen ${ }^{2}$.

9. Partizipatorisches Arbeiten VIII mit Eric Wagner (Performer aus Mecklenburg).

\section{Anmerkungen}

1 Brecht, Berthold (1927): Gedichte. Frankfurt/Main 2002.

2 Ruping, Bernd/Prüllage, Reinhard (Hg.) (2006): Lingen. Stadt der Kulturen. sang der maschinen. Die Performance im Eisenbahnausbesserungswerk am Campus Lingen. Lingen.

\section{Literatur}

Brecht, Berthold (1927/2002): Gedichte, Frankfurt/Main.

Ruping, Bernd, Reinhard Prüllage (Hg.) (2006): Lingen. Stadt der Kulturen. sang dermaschinen. Die Performance im Eisenbahnausbesserungswerk am Campus Lingen. Lingen. 
hodul of c.oos canivatas gorbse $7 a r$

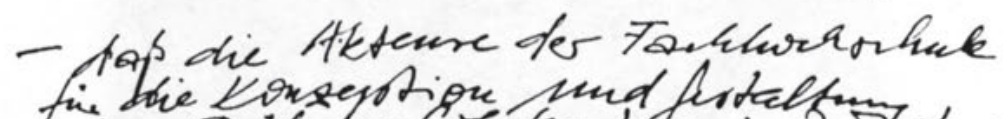
fin bie Konsepsion und fertalt is be Dilutencicdes tprie saft torem,

is be dar werden. wodicen eving hisigefinen:

Dole: ons

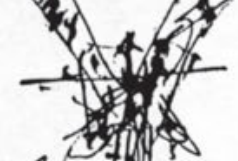

I dein inder thalle ${ }^{S}$ den Teclunikgoint

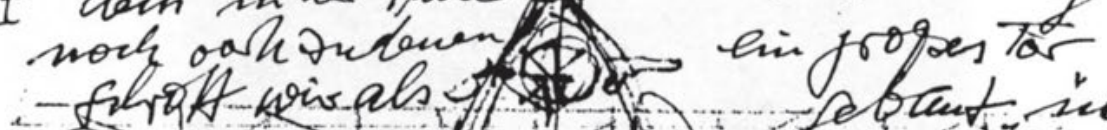
epant siber. ingtry for: acoutg ingel de forhighte
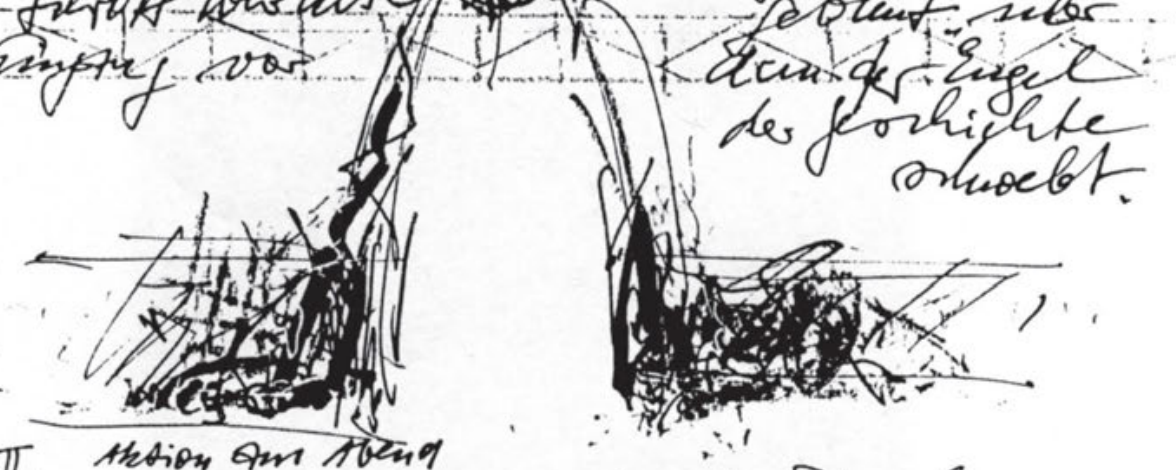

II thation an town

Vor and-deen Eintreften der Bemaler

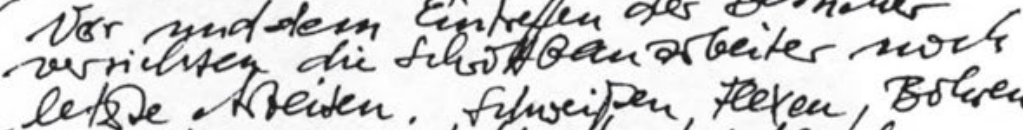

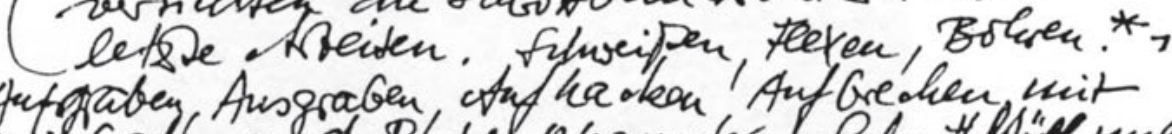

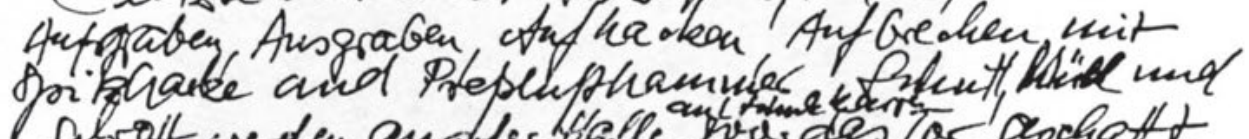

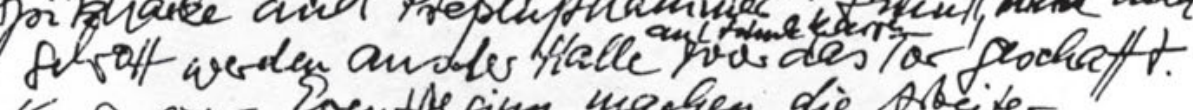

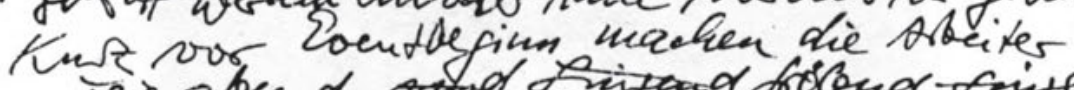

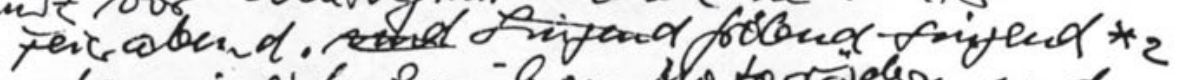

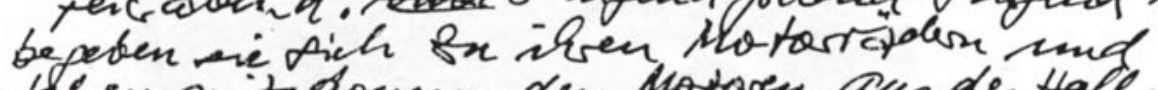
faren mit hownern den Movoren aus der thalle unsik sa aras sropse Tar von Nowgorad"

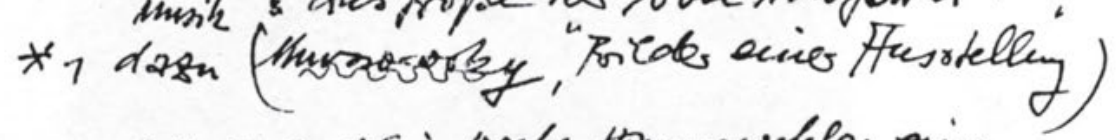

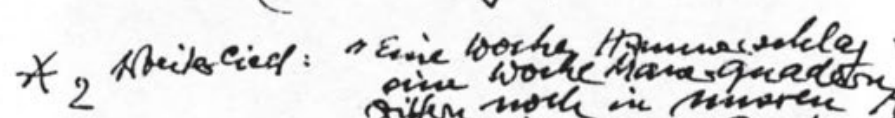

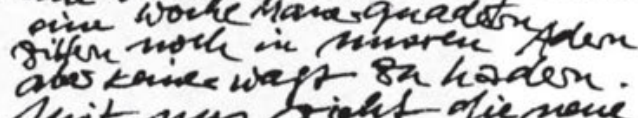

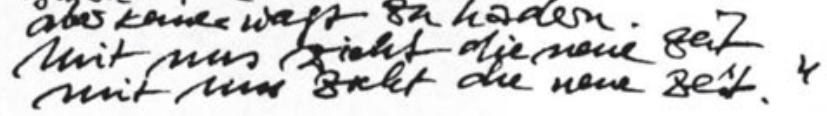



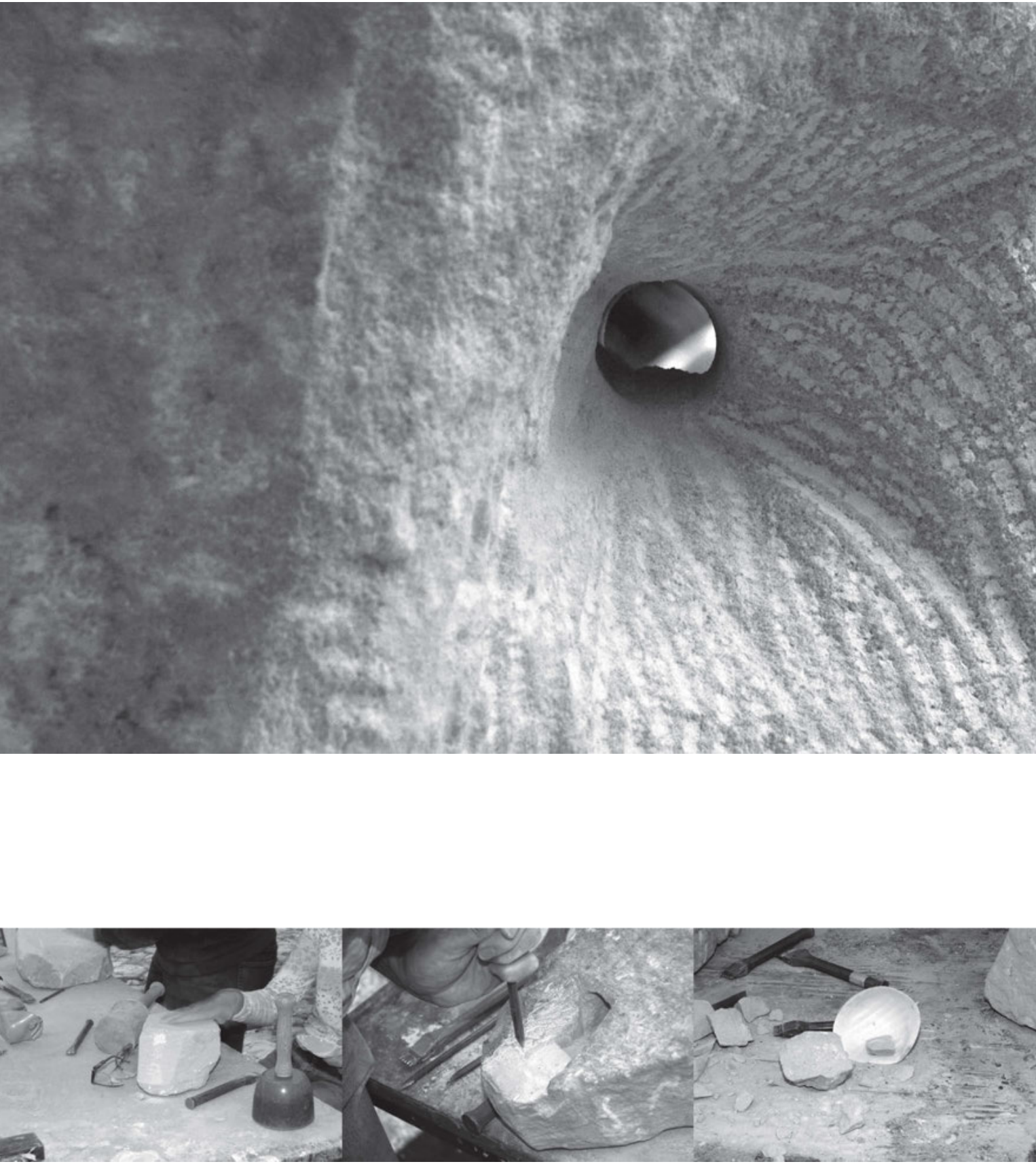